$13^{\text {th }}$ International Conference on

AEROSPACE SCIENCES \& AVIATION TECHNOLOGY,

ASAT- 13, May 26 - 28, 2009, E-Mail: asat@mtc.edu.eg

Military Technical College, Kobry Elkobbah, Cairo, Egypt

Tel : +(202) $24025292-24036138$, Fax: +(202) 22621908

\title{
A Review of More-Electric Aircraft
}

\author{
A. A. AbdElhafez ${ }^{*}$ A. J. Forsyth**
}

\begin{abstract}
The More-Electric Aircraft (MEA) underlines the utilization of the electrical power to power the non-propulsive aircraft systems. Adopting the MEA achieves numerous advantages such as optimizing the aircraft performance and decreasing operating and maintenance costs. Moreover, the MEA reduces the emission of the air pollutant gases from the aircraft, which can contribute in solving the problem of climate change. However, the MEA put some challenge on the aircraft electrical system either in the amount of the required power or the processing and management of this power. This paper introduces a review for the MEA. The review includes the different options of generation and power system architectures.
\end{abstract}

Keywords: MEA, generation, power electronics, power system

\section{Introduction}

Recently, the aircraft industry has achieved a tremendous progress either in civil or military sectors, for example some currently commercial airliners operate with weights over 300000 $\mathrm{kg}$ and have the ability to fly up to $16000 \mathrm{~km}$ in non-stop journey at speed of $1000 \mathrm{~km} / \mathrm{h}$ [1-4].

The non-propulsive aircrafts systems are typically driven by a combination of different secondary power types such as hydraulic, pneumatic, electrical and mechanical power[1-3, 57]. These powers are extracted from the aircraft main engine by different disciplines. For example, mechanical power is obtained from the engine by a driven shaft and distributed to a gearbox to drive lubrication pumps, fuel pumps, hydraulic pumps and electrical generators [1, 5-7]. Pneumatic power is extracted by a bleeding compressor and used to drive turbine motors for the engine start systems, wing anti-icing and Environmental Control Systems (ECS), while electrical power and hydraulic power are distributed throughout the aircraft for driving subsystems such as flight control actuators, landing gear brakes, utility actuators, avionics, lighting, galleys, and weapon system in case of military aircraft [1, 5-9].

This combination has been always debated, because these systems are becoming rather complicated, and their interactions reduce the efficiency of the whole system. For example, a easily handled [1, 8, 10-14]. Furthermore, the market prospects for reducing the cost of simple leak in pneumatic or hydraulic system results in a grounded aircraft and inconvenient

\footnotetext{
${ }^{*}$ Lecturer, Dr., Electrical Engineerig, Faculty of Engineering, Assiut university, Assiut, Egypt /Elhafez@aun.edu.eg

** Head of power conversion group, Professor, Power Conversion Group, Electrical and Electronic Engineering school, Faculty of Engineering and Physical sciences, University of Manchester, Sackville Street, P.O 88, M60 1DQ/ Andrew.Forsyth@manchester.ac.uk 
ownership and the future legislation regarding the climate change require a radical change to the entire aircraft, since it is not sufficient to optimize the current aircraft sub-systems and components individually to achieve these goals [1-23].

The trend is to use the electrical power for extracting and distributing the non-propulsive powers. This trend is defined as MEA. The MEA has been questioned for several decades since W.W. II [12-15]. Nevertheless, due to the lack of electric power generation capabilities and volume requirements of the required power conditioning equipments, the focus has been drifted into the conventional power types.

The recent breakthroughs in the field of power electronic systems, fault-tolerant electric machines, electro-hydrostatic actuators, electromechanical actuators, and fault-tolerant electrical power systems have renewed the interest in the MEA [1-23]. The comparison between conventional aircraft subsystems and MEA subsystems is shown in Fig.1 [4].

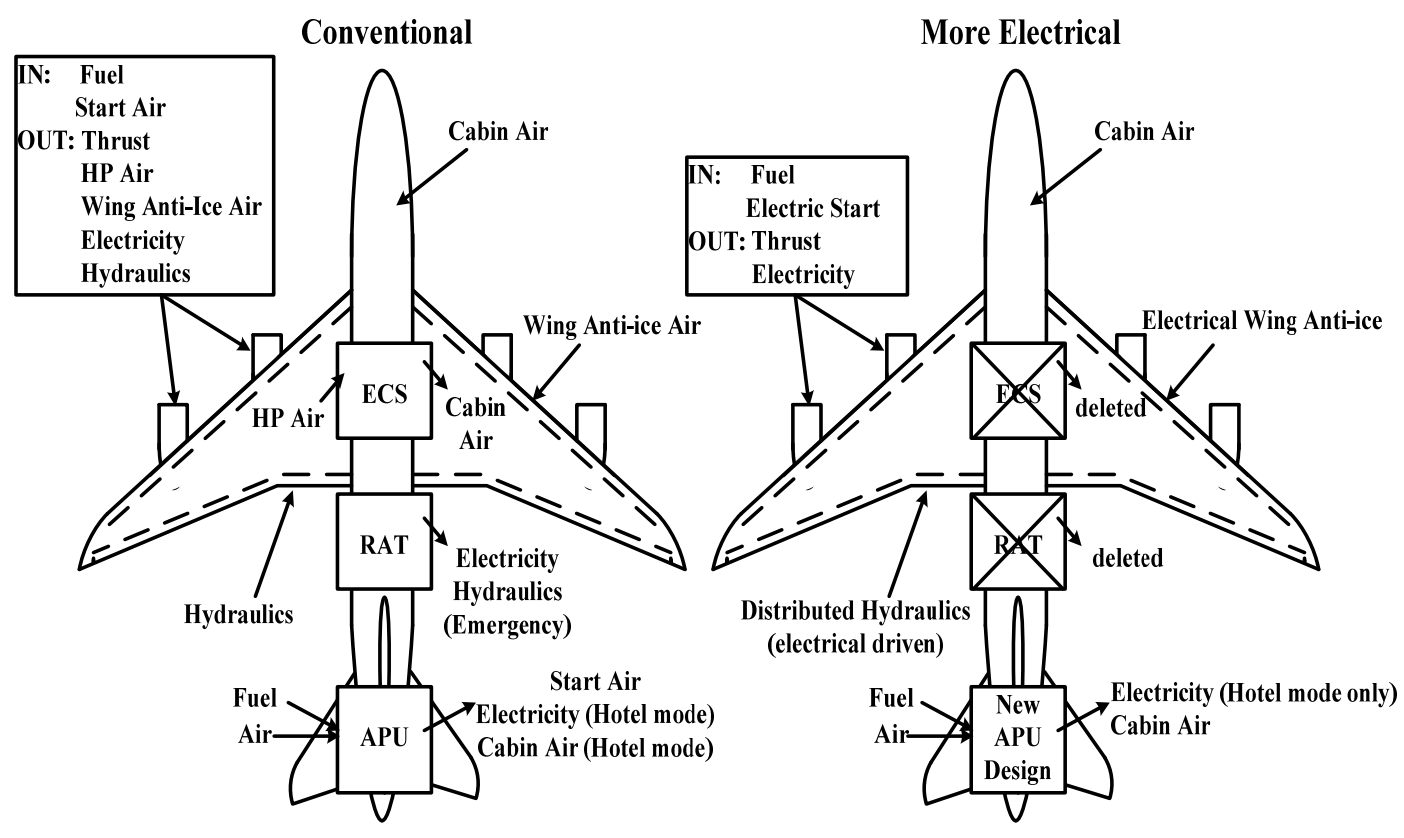

Fig. 1. Comparison between conventional aircraft systems and MEA systems [4]

The adoption of MEA in the future aircraft either in civil or military sectors results in tremendous benefits such as:

1. Removing hydraulic systems improves the aircraft reliability, vulnerability, and reduces complexity, redundancy, weight, installation and running cost [8, 12-14].

2. Employing electrical starting for the aero-engine through the engine starter/generator eliminates the engine tower shaft and gears, power take-off shaft, accessory gearboxes, and reduces engine starting power especially in the cold conditions [2, 5, 18, 20].

3. Using the Advanced Magnetic Bearing (AMB) system, which could be integrated into the internal starter/generator for both the main engine and auxiliary power units, allows for oil-free, gear-free engine [1-3, 5, 8-11, 15, 18]. 
4. Using a fan shaft generator that allows emergency power extraction under windmill conditions, removes the conventional inefficient single-shot ram air turbine, which increases the aircraft reliability, and survivability under engine-failure conditions[1, 6, 15]

5. Replacing the engine-bleed system by electric motor-driven pumps reduces the complexity and the installation cost[5].

In general, adopting MEA revolutionizes the aerospace industry completely, and significant improvements in terms of aircraft-empty weight, reconfigureability, fuel consumption, overall cost, maintainability, supportability, and system reliability, can be achieved $[2,5,6,8,10-15$, $18,19,24]$.

On the other side, the MEA concept requires increased demands on the aircraft electric power system in areas of power generation and handling, reliability, and fault tolerance, which mandates innovations in power generation, processing, distribution and management systems $[1-11,15,18-21,24]$.

The next sections briefly discuss a general overview of the electrical power generation, processing, distribution and management systems in MEA.

\section{Electric Power Generation in MEA}

The MEA represents recently the major driver for increasing the generation of the electric power [1, 3, 5-11, 15, 22]. Moreover, the MEA directs the research into new generation options. Fig, 2 [7] shows different electric power generation disciplines used in aircraft. These schemes are summarized in the following.

1. The constant frequency (CF) options are the most common. However, the need for unreliable gearbox to match between the engine speed and the generator requirements of fixed speed, makes the CF expensive and cumbersome[1, 5-7, 9, 24]. The CF is alternatively termed Integrated Drive Generator (IDG).

2. Variable Speed Constant Frequency (VSCF) DC link system is now the preferred option for the most new military aircraft application and some commercial aircraft. Currently, the range of VSCF DC link system has been widened due to the recent advancements in field of high power electronic switches. VSCF DC link option is generally characterized by simplicity and reliability[1, 6, 7, 11, 23]

3. Variable Speed Constant Frequency (VSCF) Cycloconverters convert directly the variable frequency AC input power into AC power with fixed frequency and amplitude [1, 6, 7]. The power generation efficiency of the cycloconverters increase as lagging power factor decrease, which would be beneficial if this technique is applied to motor loads with significant lagging power factors [1].

4. Variable Frequency (VF), typified frequency wild, is the most recent electric power generation contender. The promising features of VF are the small size, weight, volume, and cost as compared with other aircraft electrical power generation options. Also VF offers a very cost-effective source of power for the galley loads, which presents a major proportion in aircraft electric system loads. However VF may pose significant risk at higher power levels, particularly with high power motor loads; furthermore, the cost of motor controllers required due to the variation in the supply frequency, need to be taken into consideration when assessing the VF [1, 4, 6-8, 22]. 


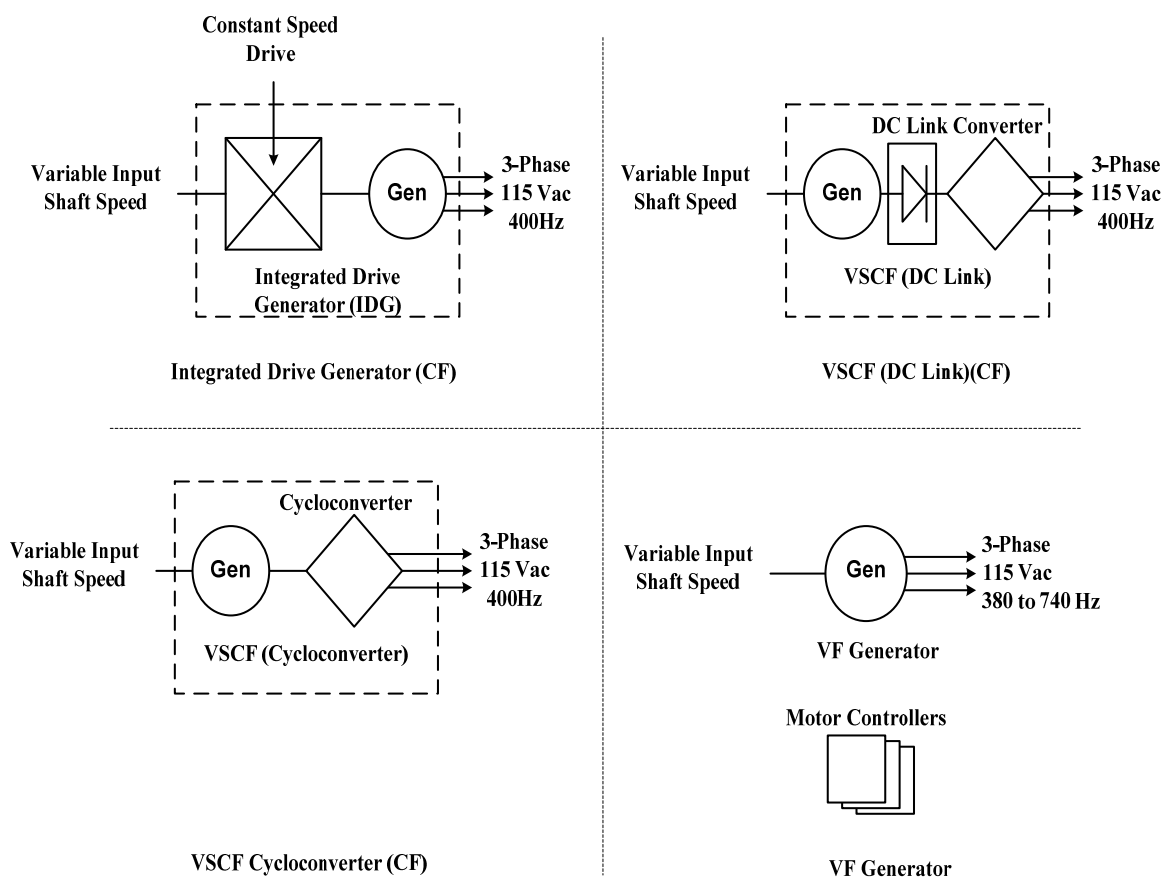

Fig. 2. Aircraft Electrical Power Generation Options [7]

The current generator technology employed on most commercial and military aircraft is the three-stage wound field synchronous generator [25]. This machine is highly reliable and inherently safe, as the field excitation can be removed, which de-energizes the machine. Therefore, the rating of the three-stage synchronous generator has increased over the years reaching to 150KVA [25] on the Airbus A380. However, the anticipated increased electrical power generation requirements on the MEA suggests that the high power generators may be attached directly to the engine, mounted on the engine shaft and used for the engine start in Integral Starter/Generator (IS/G) scheme. The harsh operating conditions and the high ambient temperatures push most commonly materials close or beyond their limits, therefore innovations in materials, processes and thermal management systems are required.

Induction, switched reluctance, and permanent magnet machine types [25-45] have been considered for application in MEA due to their rugged features. However, the induction generator requires complex power electronics and is considered unlikely to have the power density of the other machines [27-30].

The Switched Reluctance (SR) machine has a very simple robust structure, and can operate over a wide speed range. The power electronics is comparatively simple. Moreover, the machine is inherently fault-tolerant [25, 31-35, 38-40]

The fault-tolerant Permanent Magnet (PM) generator is considered to be one of the most attractive options for the MEA. It has a high $\mathrm{kW} /$ mass ratio and a good efficiency throughout a wide speed range. Additionally, the reliability, ruggedness, and ease of cooling are also positive features [38-46]. 


\section{Electric Power Processing in MEA}

There are many occasions within the aircraft electrical system where it is required to convert the electrical power from one level/form to another level/form. Thus the aircraft electrical system has plenty of power electronic circuits such as AC/DC, DC/DC, DC/AC and matrix converters[21, 46-48]. The general requirements, which these circuits should satisfy, are:

1. The system should have light weight and small size.

2. The system should be fault-tolerant, which implies its ability to continue functioning under abnormal conditions without much loss in the output power or degradation of the performance.

3. The system should be efficient and have the ability for operation in harsh conditions such as high temperature and low maintenance.

Innovations in the area of power electronic components are required to enable realization of MEA. Wide-BandGap (WBG) High-Temperature Electronics (HTE) is an example of these developments. The devices manufactured from WBG-HTE are capable of operating at both higher temperatures $\left(600{ }^{\circ} \mathrm{C}\right)$ [20] and higher efficiencies then to Si-based devices $\left(-55{ }^{0} \mathrm{C}\right.$ to 125 0C). The anticipated benefits of using WBG-HTE are:

1. Reduction in flight control system and improved reliability [3, 8, 9, 20, 21]

2. Reduction/Elimination of ECS required to cool power management and distribution and flight control electronics $[2,5,18,20]$

3. Reduction in engine control system weight and increased reliability using a distributed processing architecture

4. Improved reliability and maintainability of stores management system avionics $[3,8,9$, 20, 21]

The big challenge for the power electronic circuits in the aircraft is the size of the passive components, as the current components usually have large size, especially for the high power level expected in the MEA. However, the on-going research in the design and fabrication of the passive components for MEA gives some optimistic results. For example, some advanced polymer insulation materials such as Eymyd, L-30N, and Upilex S [11] have the ability to operate over a wide temperature range $\left(-269{ }^{0} \mathrm{C}\right.$ to $\left.300{ }^{0} \mathrm{C}\right)$. Also these materials can withstand the environmental conditions such as humidity, ultraviolet radiation, basic solution and solvent at high altitudes[11]. Another example is the ceramic capacitors, which offers remarkable advantages in volumetric density compared to other capacitor technology [49].

\section{Power Distribution and Management System in MEA}

The aircraft power system usually consists of a combination of $115 \mathrm{~V} 400 \mathrm{~Hz}$ AC for large loads and 28V DC for avionics, flight control and battery-driven vital services. However, adopting the new generation options as VF requires using power electronics to convert all the motor/generator outputs into a single high-Voltage DC Distribution system. The value of the system voltage is suggested to be 270,350 or $540 \mathrm{~V}$ [1-19]. Using a high value for the distribution system has the advantages of reducing the weight, the size and the losses, while increasing the levels of the transmitted power. The exact value, however, is determined by a number of factors such as, the capabilities of DC switchgear, the availability of the components and the risk of corona discharge at high altitude and reduced pressure [50]. 
Four different candidates for implementing the proposed Electrical Power Distribution System (EPDS) in the MEA are briefly reviewed in the following. These are:

1. Centralized EPDS

2. Fault-Tolerant EPDS

3. Advanced Electric System (AES)

4. Semi-distributed EPDS

\subsection{Centralized EPDS}

The centralized EPDS is a point-to-point radial power distribution system as shown in Fig. 3. It contains only one distribution centre. The generators supply this distribution centre, where the electrical power are processed and fed to the different aircraft electrical loads. The distribution centre is normally positioned in the avionics bay, Fig. 3, where the point of voltage regulation is located. In this system, each load is supplied individually from the power distribution centre $[1,51]$.

The main advantages of the centralized EPDS are :

1. Ease of maintenance, since all equipments is located in one place, avionics bay.

2. Decoupling between the loads; thus the disturbance in a load is not transferred to the other.

3. Fault-tolerant, as the main buses are highly protected.

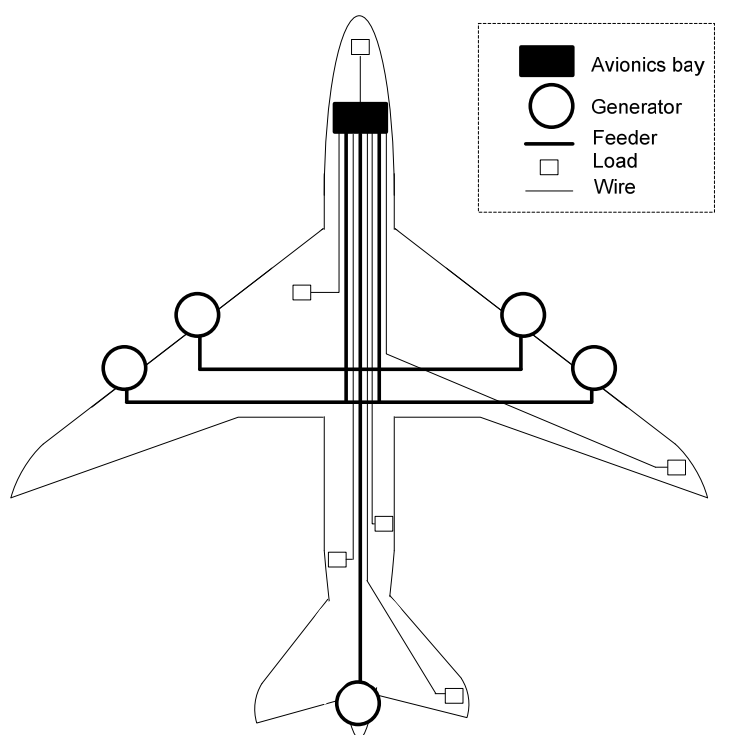

Fig. 3. Centralized EPDS for the MEA [51]

However, the centralised EPDS has serious drawbacks. These includes

1. The need to run wires to each load from the avionics bay, which increases the cost and the Volume and reduces the reliability.

2. The faults in the distribution centre affect all the loads.

3. The difficulty of the system upgrading. 


\subsection{Fault-Tolerant EPDS}

The typical fault-tolerant EPDS for two engine aircraft consists of two switches matrices, six multi-purpose converter, six generators and anticipated loads as shown in Fig. 4.

The electrical power sources are connected to the source switch matrixes, while the loads are connected to the Load switch matrixes [22]. The switches in the matrices can be constructed with conventional contactors, unique new multi-position rotary contactors or solid-state contactors. The fault-tolerant EPDS has the advantages of:

1. The ability to start the aircraft engine by using Generator/Starter scheme

2. High redundancy

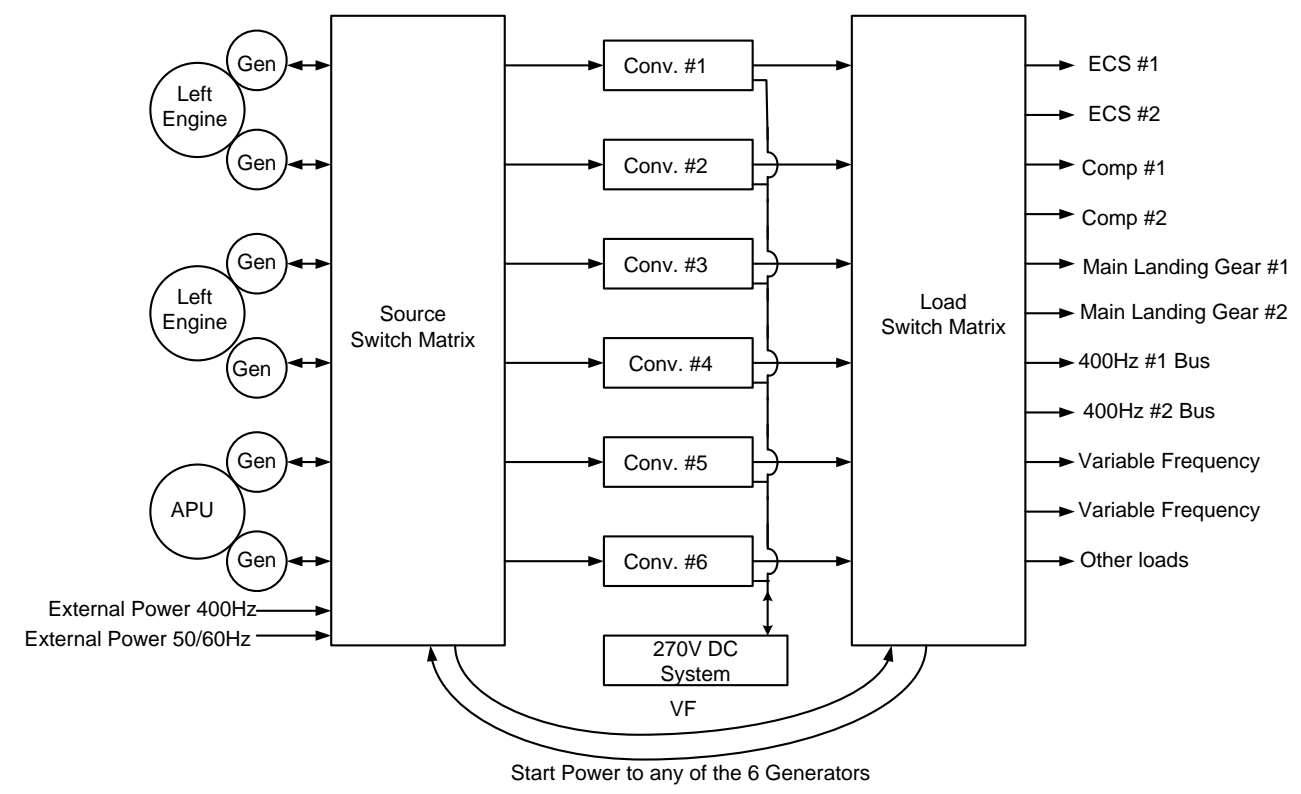

Fig. 4. Block diagram of fault-tolerant EPDS [22]

The fault-tolerant EPDS as shown in Fig. 4, has the disadvantage of faults in source/load switch matrices interrupts the operation of the other generators/loads.

\subsection{Advanced Electric System (AES)}

The Advanced Electric System (AES) is flexible, fault-tolerant system, which is developed to replace the conventional centralized manual or semi-automated power distribution system with a redundant microprocessor-based system. The electrical power as shown in Fig. 5 are supplied from the generators, APU, battery and ground sources to the primary power distribution, where the Contactor Control Units (CCU) and high power contactors are located. The aircraft loads are supplied via the Relay Switching Units (RSU). The AES is controlled by either of the two redundant Electrical load Management units (ELMU). The CCU performs control and protection on the power which is processed through the quad redundant AES data bus. The Remote Terminal (RT) units control the RSU. 
The AES is superior than the centralized [53]. This is because the AES has the following advantages :

1. AES reduces the aircraft life cycle cost, as the reconfiguration of the system in the event of an aircraft modification or upgrade can easily be accommodated

2. AES can detect deviant conditions of current/Voltage and provide instant load shut-off

3. A major reduction in the weight and wiring in the AES is achieved due to the elimination of circuit breaker panels from the flight deck stands.

4. The system can be easily upgraded.

5. AES provides a high fault-tolerant distribution system that is protected against over current via a fusible link in the RSU under different expected and unexpected conditions.

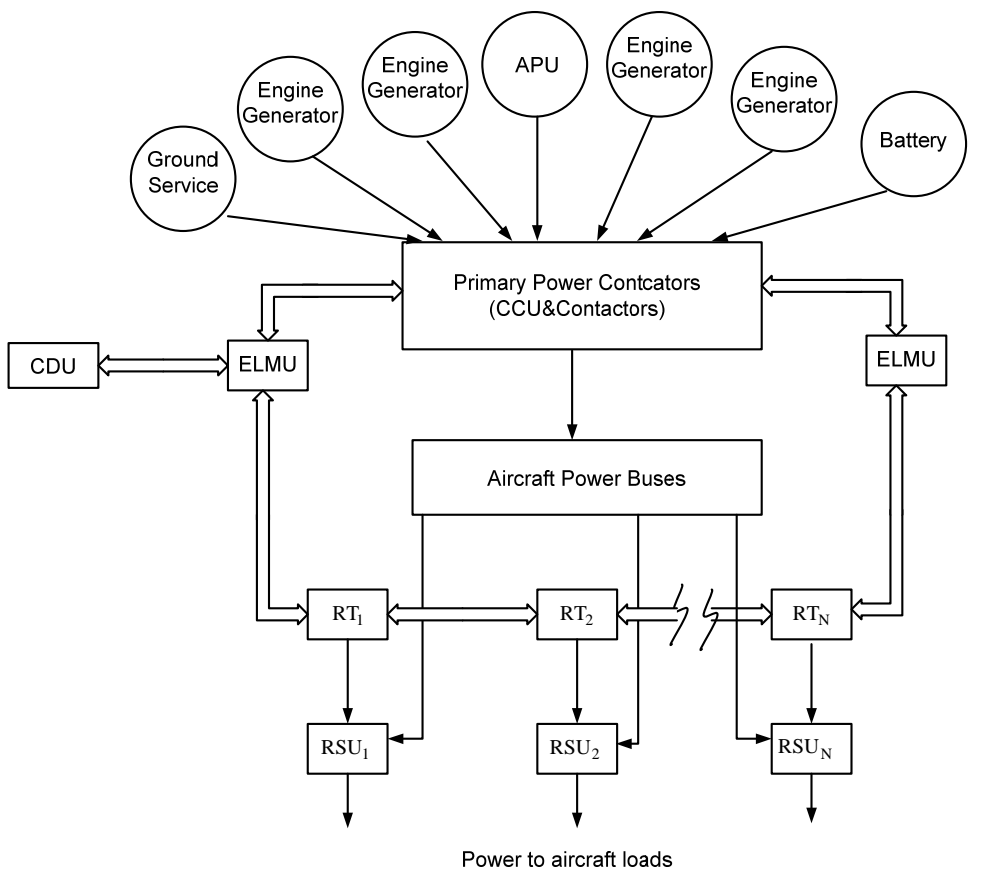

Fig. 5. Block diagram of AES [53]

The AES has the disadvantage of concentrating the distribution and the management of power supplied by the generating units/sources into a single unit; therefore a fault in this unit may interrupt the operation of all aircraft loads.

\subsection{Semi-Distribution EPS}

The main Alternative version of the conventional centralized EPDS is semi-distributed architecture. This architecture as shown in Fig. 6 utilizes a large number of Power Distribution Centers (PDCs), which are scaled down versions of PDC in the centralized system. The PDCs are distributed around the aircraft in such way to optimize the system Volume/weight and reliability. They are located a shown in Fig. 6 along the fuselage and supply the most adjacent loads [51, 53]. 
The semi-distributed EPDS has a number of advantages, such as:

1. Wires with small weight/Volume are being employed in the semi-distributed EPDS, which decreases the overall system cost and increases its efficiency and reliability.

2. Using a large number of distribution centers increases the level of redundancy in primary power distribution paths.

3. A high efficient operation of the EPDS is realized due to the reduced Voltage drops across the distribution network.

4. Locating the distribution centers near to the loads improves the system power quality, and reduces the Electromagnetic Interferences (EMI) [51, 53].

5. The system can be upgraded easily.

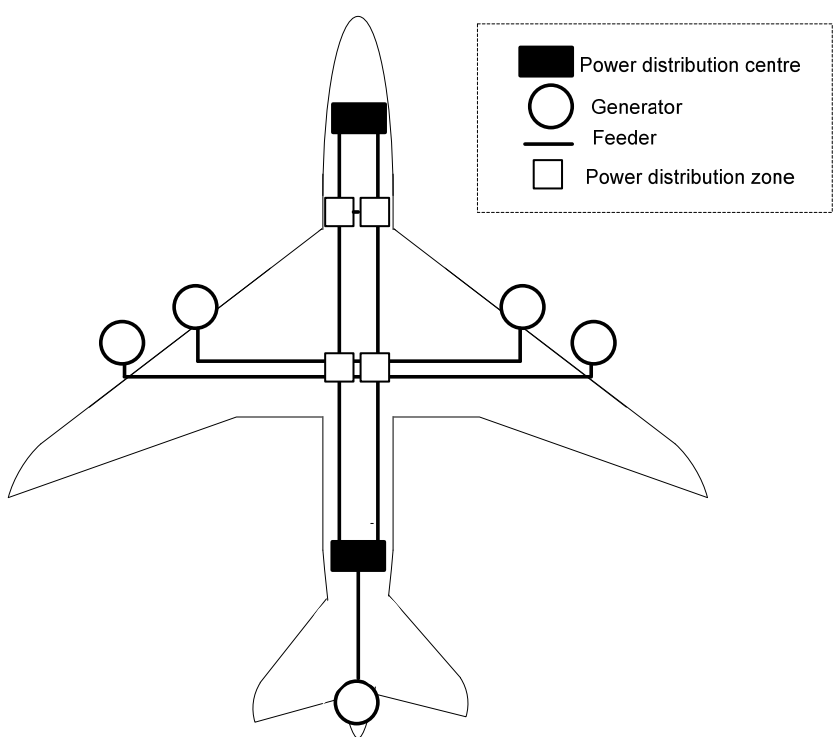

Fig. 6. Semi-distributed EPDS for the MEA [51]

In the other side, the semi-distributed has some drawbacks. These include

1. The closely coupling between the loads connected to the same PDC reduces the reliability.

2. Additional equipment is needed to perform the monitoring and control of the semidistributed EPS.

\section{Conclusion}

Replacing the conventional non-propulsive aircraft power, mechanical, hydraulic and pneumatic with single electric power is known as MEA, and considered as the future trendsetter. The MEA improves the aircraft reliability, affordability, fuel consumption. Moreover, MEA reduces cost of ownership, operation and maintenance cost. However, the implementation of MEA requires innovation in the areas of power generation, distribution and management.

Embedding the electrical generator into the aero-engine is considered to be key issue in generating the large amounts of power, as it removes the cumbersome matching gearbox. 
The SR and fault-tolerant PM machines are increasingly being adopted in the MEA, which returns to the high $\mathrm{kW} /$ mass ratio and the inherent fault tolerance.

The conventional centralized EPDS is point-to-point, radial system. This system is bulky and heavy; therefore, a number of candidate solutions were advised to replace it.

\section{References}

[1] I. Moir and A. Seabridge, Aircraft systems : mechanical, electrical, and avionics subsystems integration. London: , 2001

[2] M. J. J. Cronin, "The all-electric aircraft," IEE Review, Vol. 36,1990, pp. 309-311.

[3] R. I. Jones, "The More Electric Aircraft: the past and the future?," in IEE Colloquium on Electrical Machines and Systems for the More Electric Aircraft, , 1999, pp. 1/1-1/4.

[4] M. J. Provost, "The More Electric Aero-engine: a general overview from an engine manufacturer," in International Conference on Power Electronics, Machines and Drives, 2002, pp. 246-251.

[5] R. E. J. Quigley, "More Electric Aircraft," Proceedings of $8^{\text {th }}$ the Applied Power Electronics Conference and Exposition, APEC '93., 1993, pp. 906-911.

[6] I. Moir, "More-electric aircraft-system considerations," IEE Colloquium on Electrical Machines and Systems for the More Electric Aircraft , 1999, pp. 10/1-10/9.

[7] I. Moir, "The all-electric aircraft-major challenges," IEE Colloquium on All Electric Aircraft, , 1998, pp. 2/1-2/6.

[8] M. Howse, "All electric aircraft," Power Engineer Vol. 17, 2003, pp. 35-37.

[9] J. A. Rosero, J. A. Ortega, E. Aldabas, and L. Romeral, "Moving towards a more electric aircraft," IEEE Aerospace and Electronic Systems Magazine, Vol. 22, 2007, pp. 3-9.

[10] S. J. Cutts, "A collaborative approach to the More Electric Aircraft," The processing of International Conference on Power Electronics, Machines and Drives, PEMD 2002., 2002, pp. 223-228.

[11] J. A. Weimer, "Electrical power technology for the more electric aircraft," The processing of 12th AIAA/IEEE Digital Avionics Systems Conference, DASC 1993., 1993, pp. 445-450.

[12] M. A. Maldonado and G. J. Korba, "Power management and distribution system for a more-electric aircraft (MADMEL)," IEEE Aerospace and Electronic Systems Magazine, Vol. 14, pp. 3-8, 1999.

[13] M. A. Maldonado, N. M. Shah, K. J. Cleek, P. S. Walia, and G. J. Korba, "Power Management and Distribution System for a More-Electric Aircraft (MADMEL)program status," Proceedings of the 32nd Intersociety Energy Conversion Engineering Conference, IECEC-97., 1997, pp. 274-279 Vol.1.

[14] M. A. Maldonado, N. M. Shah, K. J. Cleek, P. S. Walia, and G. Korba, "Power management and distribution system for a more-electric aircraft (MADMEL)-program status," Proceedings of the 31st Intersociety, Energy Conversion Engineering Conference, IECEC 96. 1996, pp. 148-153 Vol.1.

[15] W. Pearson, "The more electric/all electric aircraft-a military fast jet perspective," IEE Colloquium on All Electric Aircraft 1998, pp. 5/1-5/7.

[16] L. Andrade and C. Tenning, "Design of Boeing 777 electric system," IEEE Aerospace and Electronic Systems Magazine, Vol. 7, pp. 4-11, 1992.

[17] A. Ponton and e. al, "Rolls-Royce Market Outlook 1998-2017," Rolls-Royce Publication No TS22388. 
[18] K. Emadi and M. Ehsani, "Aircraft power systems: technology, state of the art, and future trends," Aerospace and Electronic Systems Magazine, IEEE, Vol. 15, pp. 28-32, 2000.

[19] J. S. Cloyd, "A status of the United States Air Force's More Electric Aircraft initiative," Proceedings of the 32nd Intersociety Energy Conversion Engineering Conference, IECEC-97., 1997, pp. 681-686 Vol.1.

[20] K. C. Reinhardt and M. A. Marciniak, "Wide-band gap power electronics for the More Electric Aircraft," Proceedings of the $31^{\text {st }}$ Intersociety Energy Conversion Engineering Conference, IECEC 96., 1996, pp. 127 - 132.

[21] L. J. Feiner, "Power electronics transforms aircraft systems," Proceedings of the WESCON/94. 'Idea/Microelectronics'. Conference 1994, pp. 166-171.

[22] T. F. Glennon, "Fault-tolerant generating and distribution system architecture," IEE Colloquium on All Electric Aircraft, , 1998, pp. 4/1-4/4.

[23] T. L. Ho, R. A. Bayles, and E. R. Sieger, "Aircraft VSCF generator expert system," IEEE Aerospace and Electronic Systems Magazine, Vol. 3, pp. 6-13, 1988.

[24] A. C. Hoffman, I. G. Hansen, R. F. Beach, R. M. Plencner, R. P. Dengler, K. S. Jefferies, and R. J. Frye, "Advanced secondary power system for transport aircraft," 1985.

[25] G. M. Raimondi, T. Sawata, M. Holme, A. Barton, G. White, J. Coles, P. H. Mellor, and N. Sidell, "Aircraft embedded generation systems," Proceedings of the International Conference on Power Electronics, Machines and Drives, 2002, PEMD 2002., pp. 217-222.

[26] C. Cossar and T. Sawata, "Microprocessor controlled DC power supply for the generator control unit of a future aircraft generator with a wide operating speed range," Proceedings of the International Conference on Power Electronics, Machines and Drives, 2004, PEMD 2004, Vol.2 pp. 458-463.

[27] S. Ying Shing and C. E. Lin, "A prototype induction generator VSCF system for aircraft," Proceedings of the International IEEE/IAS Conference on Industrial Automation and Control: Emerging Technologies, 1995, pp. 148-155.

[28] R. C. Bansal, "Three-phase self-excited induction generators: an overview," IEEE Transaction on Energy Conversion, 2005. Vol. 20, pp. 292-299.

[29] R. C. Bansal, T. S. Bhatti, and D. P. Kothari, "Bibliography on the application of induction generators in nonconventional energy systems," IEEE Transaction on Energy Conversion, 2003. Vol. 18, pp. 433-439.

[30] F. Khatounian, E. Monmasson, F. Berthereau, E. Delaleau, and J. P. Louis, "Control of a doubly fed induction generator for aircraft application," Proceedings of the $29^{\text {th }}$ Annual IEEE Conference on Industrial Electronics Society, 2003. IECON '03. 2003, Vol.3 pp. 2711-2716.

[31] M. E. Elbuluk and M. D. Kankam, "Potential starter/generator technologies for future aerospace applications," IEEE Aerospace and Electronic Systems Magazine, Vol. 12, pp. 24-31, 1997.

[32] T. L. Skvarenina, O. Wasynczuk, P. C. Krause, C. Won Zon, R. J. Thibodeaux, and J. Weimer, "Simulation and analysis of a switched reluctance generator/More Electric Aircraft power system," Proceedings of the $31^{\text {st }}$ Intersociety Energy Conversion Engineering Conference, 1996. IECEC 96. Vol. 1. pp. 143-147.

[33] E. Richter and C. Ferreira, "Performance evaluation of a $250 \mathrm{~kW}$ switched reluctance starter generator," Proceedings of the $13^{\text {th }}$ IEEE Industry Applications Conference, 1995. Vol. 1. pp. 434-440. 
[34] C. A. Ferreira, S. R. Jones, W. S. Heglund, and W. D. Jones, "Detailed design of a 30kW switched reluctance starter/generator system for a gas turbine engine application," IEEE Transactions on Industry Applications, Vol. 31, pp. 553-561, 1995.

[35] T. L. Skvarenina, S. Pekarek, O. Wasynczuk, P. C. Krause, R. J. Thibodeaux, and J. Weimer, "Simulation of a switched reluctance, More Electric Aircraft power system using a graphical user interface," Proceedings of the $32^{\text {nd }}$ Intersociety Energy Conversion Engineering Conference, 1997. IECEC-97, 1997. Vol. 1. pp. 580-584

[36] C. Pollock and W. Chi-Yao, "Acoustic noise cancellation techniques for switched reluctance drives," IEEE Transactions on Industry Applications, Vol. 33, pp. 477-484, 1997.

[37] S. R. Jones and B. T. Drager, "Sensorless switched reluctance starter/generator performance," IEEE Industry Applications Magazine, Vol. 3, pp. 33-38, 1997.

[38] A. G. Jack, B. C. Mecrow, and J. A. Haylock, "A comparative study of permanent magnet and switched reluctance motors for high-performance fault-tolerant applications," IEEE Transactions on Industry Applications. 1996. Vol. 32, pp. 889895.

[39] B. C. Mecrow, A. G. Jack, J. A. Haylock, and J. Coles, "Fault-tolerant permanent magnet machine drives," IEE Electric Power Applications. 1996. Vol. 143, pp. 437442.

[40] P. H. Mellor, S. G. Burrow, T. Sawata, and M. Holme, "A wide-speed-range hybrid variable-reluctance/permanent-magnet generator for future embedded aircraft generation systems," IEEE Transactions on Industry Applications, 2005. Vol. 41, pp. 551-556.

[41] A. J. Mitcham, A. J. Mitcham, and N. Grum, "An integrated LP shaft generator for the more electric aircraft An integrated LP shaft generator for the more electric aircraft," IEE Colloquium on All Electric Aircraft , 1998, pp. 8/1-8/9.

[42] A. J. Mitcham, A. J. Mitcham, and J. J. A. Cullen, "Permanent magnet generator options for the More Electric Aircraft Permanent magnet generator options for the More Electric Aircraft," Proceedings of the International Conference on Power Electronics, Machines and Drives, 2002, PEMD 2002, pp. 241-245.

[43] A. J. Mitcham, A. J. Mitcham, G. Antonopoulos, and J. J. A. Cullen, "Favourable slot and pole number combinations for fault-tolerant PM machines Favourable slot and pole number combinations for fault-tolerant PM machines," IEE Colloquium on Electric Power Applications, 2004. Vol. 151, pp. 520-525.

[44] A. J. Mitcham and J. J. A. Cullen, "Permanent Magnet Modular Machines: New design Philosophy," in Electrical Drive Systems for the More Electric Aircraft oneDay Seminar, 2005, pp. 1-8.

[45] A. A. AbdEl-Hafez, R. Todd, A. J. Forsyth, and S. A. Long, "Single-Phase Controller Design for a Fault-tolerant Permanent Magnet Generator," Proceedings of the IEEE Vehicle Power and Propulsion (VPP) Conference, 2008, pp. 451-460.

[46] F. J. Chivite-Zabalza, A. J. Forsyth, and D. R. Trainer, "Analysis and practical evaluation of an 18-pulse rectifier for aerospace applications," Proceedings of the International Conference on Power Electronics, Machines and Drives, 2004, PEMD 2004. Vol. 1. pp. 338-343.

[47] G. Gong, U. Drofenik, and J. W. Kolar, "12-pulse rectifier for more electric aircraft applications," Proceedings of the IEEE International Conference on Industrial Technology, 2003. Vol. 2, pp. 1096-1101. 
[48] A. A. AbdEl-hafez, A. M. Cross, A. J. Forsyth, D. R. Trainer, and J. A. Cullen, "Single-Phase Active Rectifier Selection for Fault-tolerant Machine," Proceedings of the $3^{\text {rd }}$ IET International Conference on Power Electronics, Machines and Drives, 2006. pp. 435-439.

[49] W. N. Lawless and C. F. Clark, Jr., "Energy storage at $77 \mathrm{~K}$ in multilayer ceramic capacitors," IEEE aerospace and Electronic Systems Magazine, 1997. Vol. 12, pp. 3235.

[50] A. Brockschmidt, "Electrical environments in aerospace applications," Proceedings of the Electric Machines and Drives, 1999. International Conference IEMD '99, 1999, pp. 719-721.

[51] S. Mollov, A. J. Forsyth, and M. Bailey, "system modelling of advanced electric power distribution architecture for large aircraft," Proceedings of the SAE conference, 2000, pp. 904-913.

[52] F. L. Worth, V. H. Forker, M. J. Cronin, and N. 1990., "Advanced Electrical System (AES)," in Aerospace and Electronics Conference, 1990, pp. 400 - 403.

[53] A. M. Cross, A. J. Forsyth, and G. Mason, "modelling and simulation strategies for the electric system of large passenger aircraft," Proceedings of the SAE conference, 2002 pp. 487-495. 